\title{
IP3 - Progress towards a Global ICT Profession
}

\author{
Roger G. Johnson \\ Department of Computer Science and Information Systems \\ Birkbeck University of London \\ Malet Street, London WC1E 7HX, UK \\ r.johnsonabcs.org.uk
}

\begin{abstract}
The International Professional Practice Partnership (IP3) was formed by the International Federation for Information processing (IFIP) in 2007 to fulfill the objective of creating a global ICT profession. This start of this programme were first presented at WCC 2008 in Milan and since then major advances have taken place - both in the collective understanding of the endeavour and also measured by actual achievements. This paper will contextualise the progress of IP3 by examining: why an ICT profession is needed and why it should be on a global basis; and the progress made by IP3 in establishing a global ICT profession.
\end{abstract}

Keywords: International Professional Practice Partnership (IP3), International Federation for Information Processing (IFIP), ICT professionalism.

\section{Introduction}

In 2007 the International Federation for Information Processing (IFIP) created its International Professional Practice Partnership (IP3). This paper develops further the ideas included in earlier papers on IP3 presented at the IFIP World Computer Congress held in Milan in 2008 [1, 2, 3, 4] and provides an update on the considerable progress since then. For an external assessment of IP3, the reader is referred to a paper by Raffai, [5].

Since the autumn of 2008 the programme has grown at a considerable pace and the purpose of this paper is to provide an overview of the progress made, the major issues encountered and the plan for the immediate future.

\section{Background}

No other technology has advanced so far so fast as ICT. Every year new advances make possible information systems that were previously impractical to build. Constructing the vast systems that run on today's computers is an engineering activity that stands comparison with the greatest achievements of the nineteenth-century engineers who transformed that society. Modern information systems are now the most complex artefacts yet made by human beings. 
The scale of the achievement comes from the ability to integrate computer technology with communications technology which together can deliver information almost instantaneously around the globe.

The modern ICT system, unlike the batch processing systems of earlier days, allows individual citizens to initiate complex applications without any external mediation by skilled staff. Without any intermediation by a skilled ICT practitioner the user risks serious inconvenience from erroneous information delivered via the internet. Further, the continuing activities of criminal groups to disrupt the economic activity of both individuals and states remind us constantly of the importance of system security.

ICT is unique in its global reach. An internet transaction from one country can involve ICT systems in several others with goods being shipped from another. All of this potentially accounted for by a company registered in yet another. Unlike many professions which have devised schemes for safeguarding the public interest while facilitating free movement of individual professionals between countries, the impact of the activities of an individual ICT practitioner in one country can be felt directly and almost instantaneously around the globe without a single person leaving their desk.

Only a global initiative can adequately respond to the global dimension of this challenge. IP3 is the first attempt to provide a framework within which to begin to address this massive challenge. By bringing together ICT membership bodies from around the globe the IP3 members believe that they can establish a global framework for a global profession.

If the citizens worldwide are to receive the full benefits of ICT they must be able to depend on the integrity of the ICT systems they use. This, in turn, relies on those systems being built, maintained and operated by staff having appropriate technical skills and personal integrity.

These requirements closely match those of many older professions. The partner member societies in IP3 believe that the time is now right to create a global profession of ICT practitioners who are recognized individually and collectively as matching the standing of the older professions.

Information technology, like architecture, engineering and accounting, is now an integral part of every walk of life so ICT systems must be built and run by professionals who understand business as well as ICT.

The innate integrity of individual practitioners is not in itself enough today. Experience in every other profession shows that only by establishing and enforcing professional standards of behaviour on practitioners can the public interest be safeguarded. The total dependence of developed societies on ICT makes it far too important to be left to individual practitioners. Organisations and governments need to know that individuals' professionalism has been certified to globally recognised standards.

This requirement has been further accelerated by the advent of legislation around corporate governance, such as Sarbanes Oxley Act of 2002 (Section 404), which requires organisations to certify the quality and integrity of their IT systems.

IP3's ultimate aim is to ensure that throughout the world there are publicly recognized and accountable ICT professionals with the appropriate education, training and personal commitment who can be entrusted to deliver global ICT solutions of the highest quality. 


\section{The IP3 Approach}

The International Federation for Information Processing (IFIP) is a global federation of over 50 member societies and, through its regional affiliates, linking almost 100 national IT bodies with an aggregate membership of over half million individuals. IFIP was established by a UNESCO initiative in 1960 and remains a formal UNESCO consultative body on IT matters. It is incorporated in Austria as a international, notfor-profit, non-governmental organization.

This provides IFIP with a unique position from which to invite the ICT bodies of the world to join in a collaborative endeavour which its supporters believe can make a significant contribution to the designing, implementing and operating of ICT systems of the highest quality.

In 2007 IFIP invited a group of leading ICT societies to provide representatives to form a Task Force whose objective was to create a programme which could be rolled out across the globe and whose final goal was to establish a global ICT profession based on an agreed set of standards informed by global best practice among the ICT bodies and also other professions.

From the outset it was agreed, firstly, that the programme was not seeking to create a new institution but to create a global partnership of professional bodies. This was expected to add value to the membership proposition of existing societies and where no society currently existed to support the establishment and growth of new bodies. The programme was also committed to promoting the vision of an ICT profession whose members are publicly recognized for their adherence to a set of standards for competence and conduct and who would lead the way in delivering the maximum benefits of ICT for humanity.

Secondly, IP3 is not seeking to "re-invent wheels". Wherever possible, IP3 will seek to adopt existing material giving suitable acknowledgments to the original authors for granting the right to its use.

Thirdly, IP3 is not an examining body. IP3 sets standards for member societies to apply to their members when considering applications for certification in terms of demonstrating competence with the Core Body of Knowledge and also commitment to Continuing Professional Development (CPD). However, the way in which accredited bodies determine the competence of individuals they wish to certify is a matter for them. This could include traditional tertiary qualifications covered by the Seoul Accord, [6] or a combination of other qualifications, national or regional such as European Certification of Information Professionals, (EUCIP) [7]. What IP3 accreditors will wish to ascertain is that alone or in combination they achieve the minimum standard set down by IP3. Again, IP3 believes that certification of individual practitioners can increase interest in professional and vocational qualifications to the benefit of a range of existing examining bodies.

The first significant public exposure of the IP3 programme was at IFIP World Computer Congress (WCC) in 2008 in Milan. At the close of the Congress, 15 representatives from computer societies around the globe signed the Milan Declaration, [8]. This declared that: 
Against the background outlined in this Declaration we make the following recommendations:

1. That the international ICT profession should be founded on the essential elements of professionalism - Competences (including knowledge), Integrity, Responsibility and Accountability and Public Obligation.

2. That the assessment of competence should combine technical and non-technical competences including communication and inter-personal skills, domain or business knowledge and managerial culture

3. That the assessment of competences should take into account international ICT certificates, both vendor-neutral and as delivered by ICT Industry, and the qualifications from formal education.

4. That the purpose of the international profession is equally to recognise professionalism itself and to support both individuals and organisations to develop that professionalism.

5. That in structuring the international profession provision should be made for the recognition of an appropriate number of profiles at different levels, and that there should be clear paths of entry and career progression to accommodate individuals from the widest possible academic and experience backgrounds.

Since that declaration, IP3 members have moved rapidly forward to realize the IP3 vision for the IP3 vision for the ICT profession and to implement the procedures that are necessary. Section 4 describes in more detail the key components which have been put in place so far.

In common with usage in older professions this paper uses the term "certification" to describe the granting of public recognition to a suitably qualified practitioner as a professional and the term "accreditation" for the process of granting a professional body the right to certify individual practitioners in accordance with specific guidelines.

The basic concept underlying professionalism is the existence of a group of trained practitioners who demonstrate a continuing commitment to a set of standards governing their practice and who accept that they may be disciplined, up to losing their right to practice, if they break the standards laid down. The IP3 interpretation can be summed up in Figure 1

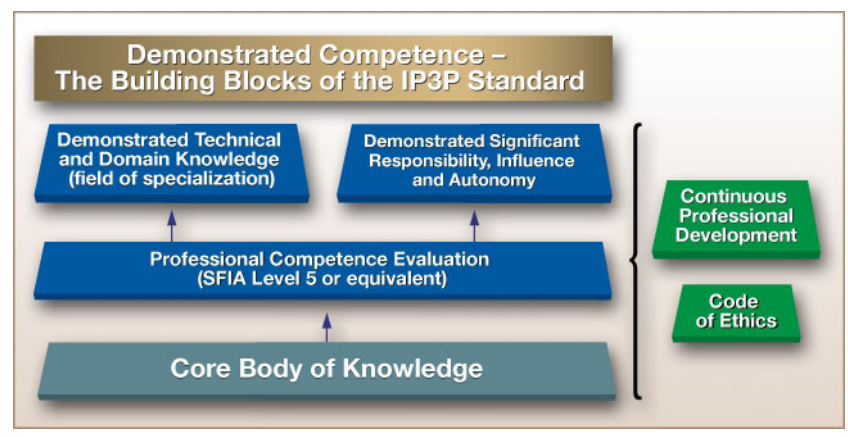

Fig. 1. The IP3 Model of ICT Professionalism

For individual practitioners, who seek public recognition as an ICT professional, IP3 asserts that, in common with members of other professions, they must: 


\section{Skills \& Competences}

- $\quad$ have their competence to practice re-assessed on a regular basis

- undertake continuous professional development

\section{Conduct and Professional Integrity}

- conform to a published code of conduct

- $\quad k n o w$, and work within, the limits of their capabilities

- be accountable for and submit to peer review of their actions

- $\quad$ explain the implications of their work to stakeholders

- have regard to the public good

\section{Responsibility to Profession}

- $\quad$ support other professionals in maintaining professional standards and developing professional competence

- $\quad$ recognise obligations to the profession as well as to their employer

- contribute to the development of the profession,

The role of IP3 is to accredit professional ICT bodies as meeting the IP3 standard for the certification of individual practitioners. IP3, therefore, has set down a set of threshold criteria to address each of the three groups of bullet points above. .Let us now consider briefly each of these three groups in turn.

\subsection{Skills and Competences}

Every profession has a Core Body of Knowledge (CBoK) which it expects all professionals to be competent with. In many professions, including ICT, this increasingly divides into two parts a Core Body of Knowledge, common to all professionals, and a Specialised Body of Knowledge of which a professional would be required to have competence in just one area. The ICT area has many CBoKs, notably the work by the ACM and IEEE-CS and similar work by the ACS and BCS, [ 9, 10,11, 12]. These documents specify the basic knowledge that is required from an applicant for professional status. The simplest form of proof is successful completion of a relevant university degree programme. Ensuring that the degree held by an applicant has provided the necessary subject coverage on a case by case basis is very time consuming and consequently most professional institutions use schemes of university course accreditation. This simplifies the processing of applications and is seen by many universities as an externally awarded proof of quality in their teaching. Sometimes the accreditation is conducted by a professional institution such as the ACS or BCS or under the auspices of a national committee such as ABET in the USA, [13].

In addition to understanding the $\mathrm{CBoK}$, new applicants are also expected to have undertaken successfully a period of supervised work at an appropriate level, typically for three years. This reflects the need for new entrants to the workplace to obtain experience of good practice as well as academic knowledge before being considered competent to practice unsupervised. IP3 has adopted a skills framework called the Skills Framework for the Information Age (SFIA), [14], to indicate the level of responsibility that IP3 expect a successful applicant to have demonstrated. The level adopted (SFIA level 5) represents work typically associated with a computing 
graduate after three years supervised employment. SFIA was originally developed in the UK, operated by a non-for-profit organization managed by its users and in use around the world.

IP3 recognises that many skills frameworks exist and is beginning a work programme of establishing mappings between some of the higher profile frameworks and SFIA. The first report has recently been received describing the mapping between SFIA and the Canadian ICTC, [15].

The CBoK used by each profession evolves as knowledge increases and in few areas as quickly as in ICT. Consequently it is surprising that ICT institutions are only latterly mandating documented Continuing Professional Development (CPD) each year as a condition for the renewal of full professional status. IP3 accreditation requires that the professional body requires an auditable record of CPD each year for each certified professional.

\subsection{Conduct and Professional Integrity}

The second area that IP3 requires a society to demonstrate is how it ensures that its professional membership behave in accordance with professional standard. The first essential is that all professional members sign up to a Code of Conduct, or a Code of Ethics. IP3 requires an appropriate Code of Conduct and again commends exemplars from leading societies. However, IP3 requires not only a commitment by each individual to a Code of Conduct but also that there exists an effective process to receive a complaint from a third party about a member, a capability to investigate the complaint and, if proven, to impose sanctions on that member. Numerous Codes of Conduct and/or Ethics have been published. An analysis was produced by the IFIP Special Interest Group 9.2.2 in 2008, [16].

In regulated professions, the penalty can extend to a life ban from practicing in the profession. However, ICT remains an unregulated profession worldwide so the most severe penalty that an institution can impose is expulsion from membership. Nonetheless, professionals know that criminal sanctions may be appropriate in cases involving, for example, criminal recklessness. However, such criminal prosecutions would be pursued by state prosecutors and not by professional bodies.

IP3 recognises that the powers of the professional institution vary from country to country and discipline to discipline. In some there are autonomous professional institutions with quasi-judicial powers to regulate and, when necessary, discipline members while in others there are combinations of nationally approved qualifications and statutory regulation. IP3 does not advance any particular model but is concerned only that, whatever the model in a given jurisdiction, the public interest is served whereby professionals are accountable for their actions. Indeed IP3 welcomes this diversity of practice believing that by studying practices around the globe best practice will emerge.

\subsection{Responsibility to the Profession}

The final area concerns the advancement of the profession and the promotion of professional values. Specifically this includes professionals accepting the need to support fellow professionals when challenged by employers or other parties in cases 
such as whistle blowing. It also lays on the professional a need to work with fellow professionals and others to develop the understanding of ICT, both its theory and practice, and to disseminate that knowledge for the public good.

A professional society should provide a variety of networking opportunities for members and also knowledge dissemination through events, special interest groups and publications.

\section{What IP3 Has Achieved}

In 2007, four societies became the founding bodies of IP3. These were:

- Australian Computer Society (ACS)

- $\quad$ British Computer Society (BCS)

- Canadian Information Processing Society (CIPS)

- Institute of Electrical \& Electronic Engineers - Computer Society (IEEECS)

In 2009 three further societies joined:

- Information Processing Society of Japan (IPSJ)

- New Zealand Computer Society (NZCS)

- Computer Society of South Africa (CSSA)

A pre-requisite for membership of IP3 is to be either a Full or Affiliate member of IFIP. In addition, member societies are either accredited or planning to seek accreditation or are committed to actively promoting professionalism in ICT. Today the IP3 member bodies have an aggregate membership (in all grades) of around a quarter of a million members.

Initially these societies operated as an IFIP Task Force but as the partnership developed it became apparent that greater formality was needed and as a result the IFIP General Assembly in August 2009 approved the creation of the IP3 Board to manage the programme, operating under delegated powers from the IFIP General Assembly. The Board membership is:

- One IFIP representative

- Representatives from each founder society

- 3 members elected by the other member bodies

- Up to 3 co-opted members

As explained in Section 3 of this paper, at the heart of the IP3 Vision is the concept of a threshold set of standards to be achieved by individual practitioners before being granted public recognition as an ICT professional. Consequently IP3 has established a Standards Committee which is charged with maintaining the IP3 statement of its threshold standard. This committee draws on global best practice to inform its work.

The Standards Committee operates independently of the Accreditation Committee whose role is to organize the accreditation of each member body on a five yearly cycle. Accreditations are overseen by IP3's Chief Assessor who chairs the Assessment Committee. When accreditation visits are undertaken, a neutral visiting team is 
selected from the panel of trained assessors. The costs of the visit are borne by the society seeking accreditation. There are two key components to the accreditation visit. Firstly, the panel will wish to assure itself of the standards adopted to approve those to be granted professional status and secondly, the panel will wish to satisfy itself as to the society's capacity to apply those standards in a rigorous manner. This is why a process of mutual support and sharing of best practice is at the centre of the IP3 programme. Full details of the IP3 accreditation process is included in the IP3 Accreditation Guidelines, [17].

\subsection{Strengthening the Professional Bodies}

IP3 relies for its success on the commitment of its member societies. Part of the ethos of the IP3 programme is the sharing of best practice. This includes a process of mentoring of societies preparing to apply for accreditation. The process of setting up the internal processes within a professional body to establish that an applicant for professional status has achieved the threshold standard is a non-trivial activity. However, most of IP3's existing members have these processes already. Some of the material is already in the public domain, such as Codes of Conduct and Common Bodies of Knowledge. Other material, such as procedures for university course accreditation or complaint investigation and disciplinary process, can be made available to societies developing professional procedures in preparation for applying for accreditation. IP3 members are encouraged to make available material to other members either on a pro bono basis or under licence agreements. In this way good practice can be shared and societies have an opportunity to recoup some or possibly all of the capital cost of developing new materials.

IP3 believes that by establishing a global network of strong, mutually supportive accredited professional bodies who

- Act as voices for the global ICT profession

- $\quad$ Provide strong support for enhancing the skills of their members

- Set and promote technical and ethical standards of professional behaviour

- Certify ICT practitioners who meet the standard

- Act to ensure serious failures by certified individuals are investigated and, if needed, appropriate penalties imposed

this will lead to

- Enhanced standards of ICT practitioner performance

- Greater public confidence in and appreciation for the work of ICT practitioners

- Increased status for the profession

- Growth in the number and skills of new practitioners

- Stronger, more effective ICT professional bodies

Support from the ICT user and supply sectors is vital to the success of IP3. Consequently IP3 has recently begun to establish a Global Industry Committee, made up of leading members of the global ICT community, to offer advice and support to the IP3 Board in developing new initiatives. This is planned to inform IP3's strategy and maximize the impact of IP3's new initiatives. 


\subsection{Accreditation}

Central to IP3 is the accreditation of member societies to grant professional status to practitioners who meet the IP3 standard. So far two societies have been successfully accredited:

- Australian Computer Society

- Canadian Information Processing Society

Between the two societies nearly 10,000 professionals are accredited as ICT professionals by IP3 accredited societies. At least two societies further are planning to seek accreditation within the next year:

- New Zealand Computer Society

- Computer Society of South Africa

Discussions are continuing with numerous other societies around the world about further expanding IP3 membership leading to more societies seeking accreditation from IP3. In this way the visibility and values associated with IP3 will be enhanced.

\section{Conclusions}

The member societies in IP3 are in no doubt that they have created an ambitious vision. However, working together under the IFIP umbrella, they believe that they are uniquely placed to promote the public understanding of the importance of creating a global ICT profession and also to offer a viable plan to implement their collective vision.

ICT has a unique capacity to provide benefits to humanity. However, IP3 believes it is too important and valuable for the technology to be trusted to the innate integrity of individual practitioners. Only a global profession, which enjoys the same trust and respect as older professions can be relied upon to deliver the full potential of the better world that ICT has the capacity to provide.

Acknowledgments. I would like to acknowledge the support and encouragement of colleagues in IP3 to provide this update on the programme.

\section{References}

1. Hughes, C.: The IFIP International Professional Practice Partnership: Informing and Transforming IT Professional Practice. In: Avison, D., Kasper, G., Pernici, B., Ramos, I., Roode, D. (eds.) Proceedings of the IFIP World Computer Congress Milan, Advances in Information Systems Research, Education and Practice. IFIP, vol. 274, pp. 135-138. Springer, Boston (September 2008)

2. Thompson, C.: IT Professional Role - Today and Tomorrow. In: Mazzeo, A., Bellini, R., Motta, G. (eds.) Proceedings of the IFIP World Computer Congress Milan September 2008, E-Government; ICT Professionalism and Competences. IFIP, vol. 280, pp. 69-80. Springer, Boston (2008) 
3. Johnson, R.: International Professional Practice Partnership (IP3) - Role and Responsibilities of National Societies. In: Mazzeo, A., Bellini, R., Motta, G. (eds.) Proceedings of the IFIP World Computer Congress Milan September 2008, E-Government; ICT Professionalism and Competences. IFIP, vol. 280, pp. 165-171. Springer, Boston (2008)

4. Hughes, C.: International Professional Practice Partnership (IP3) - Overview. In: Mazzeo, A., Bellini, R., Motta, G. (eds.) Proceedings of the IFIP World Computer Congress Milan September 2008, E-Government; ICT Professionalism and Competences. IFIP, vol. 280, pp. 159-163. Springer, Boston (2008)

5. Raffai, M.: International Program for Standardizing Global IT Profession SEFBIS Journal. John v Neumann Computer Society, Hungary 3 (2008), HU ISSN 1788-2265

6. Seoul Accord, http: //www. seoulaccord.com

7. European Certification of Information Professionals (EUCIP), http: / / www. eucip.org

8. WCC 2008 Declaration on ICT Professionalism and Competences, IFIP WCC 2008, Milan (2008), http://www.ifip.org/images/stories/ifip/public/ Announcements/wcc08-ict-p\&c-declaration.pdf

9. ACM, IEEE-CS, Curriculum Guidelines for Undergraduate Programs in Information Technology (2008), http://www.acm.org//education/curricula/ IT2008\%20Curriculum.pdf

10. Software Engineering Body of Knowledge, IEEE-CS (2004), http: / / www. swebok. org

11. ACS Professional Standards and Education - Core Body of Knowledge (October 2008) https: / / www.acs.org.au/attachments / ACSCBOKWorkingPaper2008.pdf

12. CITP Breadth of Knowledge Test Syllabus, BCS The Chartered Institute for IT (November 2009), http: / / www. bcs.org/upload/pdf/citp-bok-syllabus.pdf

13. ABET, Inc., http: //www. abet.org

14. Skills Framework for the Information Age, SFIA (2008), http: / / www. sfia.org . uk

15. Information and Communication Technology Council, Occupational Skills Profile Model, Canada (2009), http: / / www. ictc-ctic.ca/en/content.aspx?id=76

16. Berleur, J., et al.: Ethics of Computing Committees: Suggestions for Function. In: Form and Structure. IFIP SIG 9.2.2, IFIP Press (2008)

17. IP3 Application and Accreditation Guidelines, IP3 (September 2008), http: / / www . ipthree. org/images / IP3 / application\%2 0 and\%2 0 assess ment:20guidelines_final.pdf 